\title{
Changes in 3-month mineral and bone disorder patterns were associated with all- cause mortality in prevalent hemodialysis patients with secondary hyperparathyroidism
}

\author{
Chihiro Kato ${ }^{1+}$, Naohiko Fujiii ${ }^{2+}$, Chisato Miyakoshi ${ }^{3,4,5}$, Shinji Asada ${ }^{1 *}$ (D, Yoshihiro Onishi ${ }^{5}$, Shingo Fukuma ${ }^{5,6,7}$,
} Takanobu Nomura', Michihito Wada ${ }^{1}$, Masafumi Fukagawa ${ }^{8}$, Shunichi Fukuhara ${ }^{3}$ and Tadao Akizawa ${ }^{9}$

\begin{abstract}
Background: There is limited evidence on the association between short-term changes in mineral and bone disorder parameters and survival in maintenance hemodialysis patients.

Methods: We investigated the association between changing patterns of phosphorus, calcium and intact parathyroid hormone levels and all-cause mortality in hemodialysis patients with secondary hyperparathyroidism. Each parameter was divided into three categories (low $[\mathrm{L}]$, middle $[\mathrm{M}]$ and high $[\mathrm{H}]$ ), and the changing patterns between two consecutive visits at 3-month intervals were categorized into nine groups (e.g., L-L and M-H). The middle category was defined as 4.0-7.0 mg/dL for phosphorous, $8.5-9.5 \mathrm{mg} / \mathrm{dL}$ for calcium and 200-500 pg/mL for intact parathyroid hormone. Adjusted incidence rates and rate ratios were analyzed by weighted Poisson regression models accounting for time-dependent exposures.
\end{abstract}

Results: For phosphorus, shifts from low/high to middle category (L-M/H-M) were associated with a lower mortality compared with the L-L and $\mathrm{H}-\mathrm{H}$ groups, whereas shifts from middle to low/high category $(\mathrm{M}-\mathrm{L} / \mathrm{M}-\mathrm{H})$ were associated with a higher mortality compared with the M-M group. For calcium, shifts from low/middle to high category $(\mathrm{L}-\mathrm{H} / \mathrm{M}-\mathrm{H})$ were associated with a higher mortality compared with the $\mathrm{L}-\mathrm{L}$ and $M-M$ groups, whereas shifts from high to middle category (H-M) were associated with a lower mortality compared with the $\mathrm{H}-\mathrm{H}$ group. For intact parathyroid hormone, shifts from low to middle category $(L-M)$ were associated with a lower mortality compared with the L-L group.

Conclusions: Changes in the 3-month patterns of phosphorus and calcium toward the middle category were associated with lower mortality. Our study also suggests the importance of avoiding hypercalcemia.

Keywords: Changing pattern, CKD-MBD, Hemodialysis, Secondary hyperparathyroidism, Mortality

\footnotetext{
*Correspondence: shinji.asada.qd@kyowakirin.com

${ }^{\dagger}$ Chihiro Kato and Naohiko Fujii contributed equally to this work.

${ }^{1}$ Medical Affairs Department, Kyowa Kirin Co., Ltd, Otemachi Financial City

Grand Cube, 1-9-2 Otemachi, Chiyoda-ku, Tokyo 100-0004, Japan

Full list of author information is available at the end of the article
}

(c) The Author(s). 2020 Open Access This article is licensed under a Creative Commons Attribution 4.0 International License, which permits use, sharing, adaptation, distribution and reproduction in any medium or format, as long as you give appropriate credit to the original author(s) and the source, provide a link to the Creative Commons licence, and indicate if changes were made. The images or other third party material in this article are included in the article's Creative Commons licence, unless indicated otherwise in a credit line to the material. If material is not included in the article's Creative Commons licence and your intended use is not permitted by statutory regulation or exceeds the permitted use, you will need to obtain permission directly from the copyright holder. To view a copy of this licence, visit http://creativecommons.org/licenses/by/4.0/ The Creative Commons Public Domain Dedication waiver (http://creativecommons.org/publicdomain/zero/1.0/) applies to the data made available in this article, unless otherwise stated in a credit line to the data. 


\section{Background}

High serum phosphorus (P) and calcium (Ca) concentrations measured at single time points are associated with all-cause and cardiovascular mortality in hemodialysis patients [1, 2]. It has been shown that the importance of maintaining $\mathrm{P}$ and $\mathrm{Ca}$ levels on prognosis by measuring their concentrations at multiple time points [3-6].

In the Mineral and Bone Disorder Outcomes Study for Japanese CKD Stage 5D Patients (MBD-5D), a prospective observational study conducted in hemodialysis patients with secondary hyperparathyroidism (SHPT) in Japan, high $\mathrm{P}$ and $\mathrm{Ca}$ levels correlated with increased mortality, while no clear correlation was observed for high intact parathyroid hormone (iPTH) levels [3]. Moreover, it has been found that instability in P, Ca and iPTH levels can influence prognosis, and the importance of maintaining $\mathrm{P}$ and $\mathrm{Ca}$ levels within specific ranges has been consistently suggested in the prospective observational studies conducted in Europe and North America [7-10] For iPTH, the only observation was that low iPTH levels may pose a risk of increased mortality [10]. However, in these prospective observational studies, variations in $\mathrm{P}, \mathrm{Ca}$ and $\mathrm{PTH}$ levels were evaluated at 6- or 12 -month intervals, which were longer than in daily clinical practice $[7,8,10]$.

The Kidney Disease Improving Global Outcomes (KDIGO) Clinical Practice Guidelines for chronic kidney disease-mineral and bone disorder (CKD-MBD) suggested that the reasonable frequency for evaluating these parameters is every 1-3 months for $\mathrm{Ca}$ and $\mathrm{P}$ and every 3-6 months for PTH, although the evidence level was "Not Graded" [11]. Therefore, we investigated the association between all-cause mortality and changes in MBD-related parameters every 3 months, which is more frequent than the previously-reported 6- or 12-month intervals, in Japanese hemodialysis patients with SHPT.

\section{Methods}

Study design and study population

MBD-5D was a multicenter, prospective observational study of maintenance hemodialysis patients with SHPT [12]. The eligibility criteria were as follows: (i) patients undergoing hemodialysis and (ii) patients with $\mathrm{iPTH} \geq$ $180 \mathrm{pg} / \mathrm{mL}$ (according to the Japanese Society for Dialysis Therapy [JSDT] guidelines [13]) or receiving vitamin D receptor activator (VDRA) treatment. A total of 8229 patients from 86 facilities were registered, and their clinical outcomes, including all-cause mortality, were collected for 3 years. Data on prescribed medication and MBD-related parameters $(\mathrm{Ca}, \mathrm{P}$ and $\mathrm{iPTH})$ were collected every 3 months; data on other time dependent variables were collected every 6 months. Patient characteristics were shown in Table 1.
Table 1 Baseline characteristics of the study population

\begin{tabular}{|c|c|}
\hline Variable & Value \\
\hline \multicolumn{2}{|l|}{ Demographics } \\
\hline Age, years & $63(55-71)$ \\
\hline Sex, female, \% & 37.7 \\
\hline Body mass index, $\mathrm{kg} / \mathrm{m}^{2}$ & $20.9(19.0-23.3)$ \\
\hline \multicolumn{2}{|c|}{ Cause of end-stage kidney disease, \% } \\
\hline Glomerulonephritis & 45.1 \\
\hline Diabetic nephropathy & 24.2 \\
\hline Other disease & 30.7 \\
\hline \multicolumn{2}{|l|}{ Comorbidities, \% } \\
\hline Diabetes mellitus & 31.6 \\
\hline Cardiovascular disease & 60.0 \\
\hline Lung disease & 7.4 \\
\hline Liver disease & 14.1 \\
\hline Malignancy & 5.1 \\
\hline \multicolumn{2}{|l|}{ Dialysis } \\
\hline Duration of dialysis, years & $8.3(3.7-14.3)$ \\
\hline $\mathrm{Kt} / \mathrm{N}$, single pool & $1.4(1.2-1.6)$ \\
\hline \multicolumn{2}{|l|}{ Dialysate $\mathrm{Ca}, \%$} \\
\hline$<3.0 \mathrm{mEq} / \mathrm{L}$ & 52.0 \\
\hline$\geq 3.0 \mathrm{mEq} / \mathrm{L}$ & 48.0 \\
\hline \multicolumn{2}{|l|}{ Laboratory data } \\
\hline Serum albumin, g/dL & $3.8(3.5-4.0)$ \\
\hline Blood hemoglobin, g/dL & $10.5(9.8-11.2)$ \\
\hline \multicolumn{2}{|l|}{ MBD-related characteristics } \\
\hline \multicolumn{2}{|l|}{ Serum parameters } \\
\hline $\mathrm{Ca}, \mathrm{mg} / \mathrm{dL}^{\mathrm{a}}$ & $9.4(8.9-10.1)$ \\
\hline $\mathrm{P}, \mathrm{mg} / \mathrm{dL}$ & $5.5(4.6-6.3)$ \\
\hline iPTH, pg/mL & $267(197-401)$ \\
\hline History of parathyroidectomy, \% & 6.2 \\
\hline \multicolumn{2}{|c|}{ Prescription of MBD-related agents, \% } \\
\hline VDRA & 77.6 \\
\hline Intravenous & 48.4 \\
\hline Oral & 30.4 \\
\hline Phosphate binder & 85.1 \\
\hline Ca carbonate & 66.7 \\
\hline Sevelamer hydrochloride & 41.1 \\
\hline Cinacalcet hydrochloride ${ }^{b}$ & 0.0 \\
\hline
\end{tabular}

Data were derived from the subcohort $(n=3276)$ randomly selected from the study population

Continuous variables were expressed as median (interquartile range) iPTH Intact parathyroid hormone, Ca Calcium, MBD Mineral and bone disorder, $P$ Phosphorus, VDRA Vitamin $D$ receptor activator

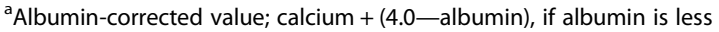
than $4.0 \mathrm{~g} / \mathrm{dL}$

${ }^{\mathrm{b}}$ Became available in January 2008 in Japan 
This study was designed as a case-cohort study; $40 \%$ of the whole cohort $(n=3276)$ was randomly selected into a subcohort, from which data were collected prospectively (Fig. 1). Data from patients who died and patients outside the subcohort were collected retrospectively.

\section{Exposures, outcomes and covariates}

The outcome of interest was all-cause mortality. MBDrelated parameters were considered time-dependent variables. Levels of each parameter were divided into three categories: low $(\mathrm{L})$, middle $(\mathrm{M})$ and high $(\mathrm{H})$, so that the middle categories $(4.0-7.0 \mathrm{mg} / \mathrm{dL}$ for $\mathrm{P}, 8.5-9.5 \mathrm{mg} / \mathrm{dL}$ for $\mathrm{Ca}$ [14] and 200-500 pg/mL for iPTH) were compatible with the middle category based on positive stratification for mortality in the previous report [6]. The changing patterns of each parameter were categorized into nine classes according to the level of that parameter measured at two consecutive visits [3]. For example, if the level of a parameter was " " at one visit and " $\mathrm{H}$ " at the following visit, then the pattern would be categorized as "L-H" (Fig. 2).

Covariates included fixed patient characteristics (age, sex, primary kidney disease, diabetes, dialysis vintage, cardiovascular disease, lung disease, liver disease, malignancy and history of parathyroidectomy) and timedependent variables that were updated at each visit (VDRAs, phosphate binders, cinacalcet, albumin, hemoglobin, body mass index, $\mathrm{Kt} / \mathrm{V}$ and dialysate $\mathrm{Ca}$ concentration).

\section{Statistical analyses}

To estimate the effect of MBD parameters on mortality, time-dependent Poisson regression models were used for time-dependent exposure and covariates such as MBD treatment by weighted inverse probability of having the specific pattern of change observed for each MBD parameter in the study.

For each 3-month interval ending at visit $t$, the incidence of clinical outcome was modeled based on the changing patterns of MBD parameters during the previous 3-month interval from visit $t-2$ (baseline) to visit $t-1$. The probability of having the pattern observed in each patient was calculated using pooled multinomial logistic regression models; for each $\mathrm{MBD}$ parameter, the other MBD parameter levels and covariates mentioned in the previous section at visit $\mathrm{t}-2$ were used as independent variables in these models.

Weighted Poisson regression was used to estimate adjusted incidence rates (aIRs) and adjusted incidence rate ratios (aIRRs). The weights were calculated using the inverse probability of having the specific pattern for each MBD parameter and the inverse of the sampling fraction $(1 / 0.4=2.5)$ for controls in the subcohort. To handle within-patient correlation, generalized estimating equations with independent working correlation and robust variance estimator were used. The results of regression analyses were presented as point estimates and 95\% confidence intervals (95\% CIs).

A post hoc analysis was performed to explore factors associated with higher Ca levels (greater than the middle category). Background characteristics of the patients in the $\mathrm{M}-\mathrm{H}$ group were compared with those in the M-L/ $M-M$ groups by calculating the standard mean difference (SMD). An SMD > 0.2 might suggest non-trivial effect size [15].

A sensitivity analysis was conducted to assess the robustness of results with longer intervals; the association between the changing patterns of MBD parameters observed during a 12-month interval and the incidence of clinical outcomes during the next 12-month interval was examined by using similar models as used for the main

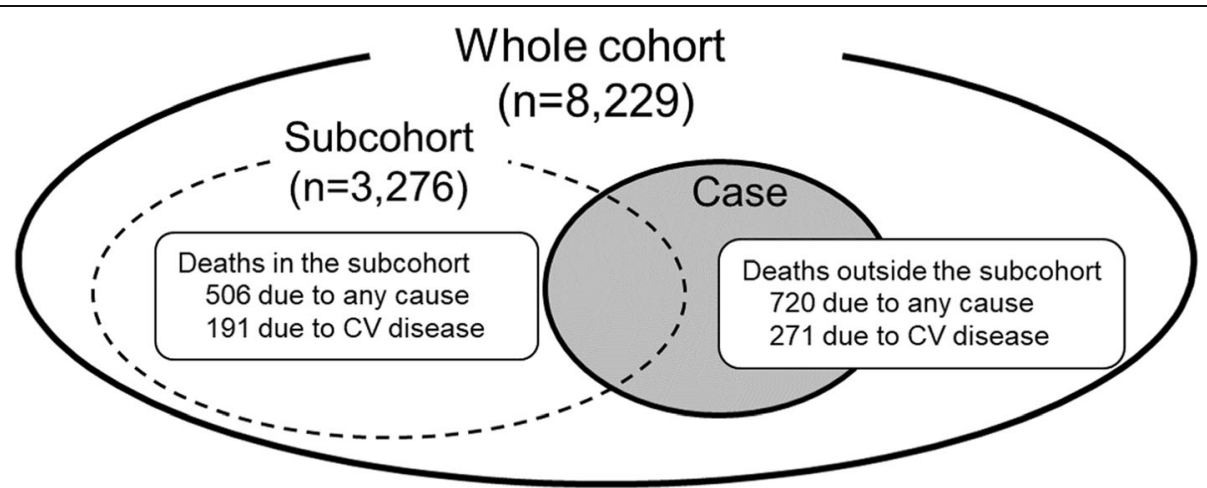

Fig. 1 Study design of the MBD-5D study.The study has a whole cohort (solid circle) of all patients enrolled and a subcohort (dotted circle) of randomly selected $40 \%$ of the whole cohort. From 86 facilities, all 8,229 dialysis patients with secondary hyperparathyroidism were registered and 3,276 patients were selected into the subcohort. In total, 1,226 all-cause deaths and 462 deaths due to cardiovascular disease were reported. CV, cardiovascular 
Changing patterns of MBD parameters

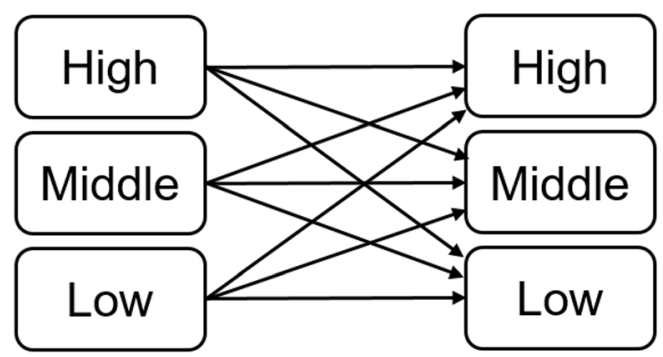

Visit $t-2$ (Baseline)

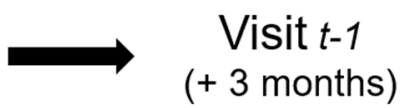

Outcome

\section{All cause mortality}

Fig. 2 Illustration of changing patterns of MBD parameters and outcome. Levels of each parameter were divided into three categories (Low, Middle and High); the middle categories were defined as 4.0-7.0 mg/dL for phosphorus, 8.5-9.5 mg/dL for calcium and 200-500 pg/mL for intact parathyroid hormone. MBD, mineral and bone disorder

analysis. SAS version 9.4 (SAS Institute Inc) was used for all analyses.

\section{Results}

Baseline characteristics and study outcome

Median P, Ca and iPTH levels were $5.5 \mathrm{mg} / \mathrm{dL}, 9.4 \mathrm{mg} /$ $\mathrm{dL}$ and $267 \mathrm{pg} / \mathrm{mL}$, respectively, at the time of enrollment (Table 1). At the last visit, median P and Ca levels remained nearly the same $(5.2 \mathrm{mg} / \mathrm{dL}$ and $9.5 \mathrm{mg} / \mathrm{dL}$, respectively), while median iPTH decreased to $165 \mathrm{pg} / \mathrm{mL}$.

During the 3-year study period, a total of 1226 allcause deaths were observed (506 among patients in the subcohort and 720 among those outside the subcohort). Total observation period was 20444 person-years. The overall mortality rate was 5.5 events/100 person-years.

\section{Association between mortality and changing patterns of MBD parameters \\ Serum phosphorus}

The aIR for patients whose P levels were maintained in the middle $(\mathrm{M}-\mathrm{M})$ category during the 3-month intervals was $4.9 / 100$ person-years, while the aIRs for those whose $\mathrm{P}$ levels were maintained in the low $(\mathrm{L}-\mathrm{L})$ and high $(\mathrm{H}-$ $\mathrm{H})$ categories were 7.4 and $11.1 / 100$ person-years, respectively (Table 2 ). The risk of mortality was significantly higher in the $\mathrm{L}-\mathrm{L}$ and $\mathrm{H}-\mathrm{H}$ groups than in the M-M group (aIRR [95\% CI]: 1.53 [1.14-2.03] and 2.28 [1.49-3.49], respectively).

Patients with P levels shifting from the middle to low/ high $(\mathrm{M}-\mathrm{L} / \mathrm{M}-\mathrm{H})$ category had a higher risk of mortality compared with those in the M-M group (Fig. 3a, middle). Changes in patterns from the low/high to middle category (L-M/H-M) were significantly associated with a lower risk of mortality compared with the unchanged patterns (L-L/H-H) (Fig. 3a, top/bottom).

\section{Serum calcium}

The aIRs for patients whose $\mathrm{Ca}$ levels were maintained in the same category during the 3-month intervals were $3.7 / 100$ person-years for the low category, $4.5 / 100$ person-years for the middle category and $6.8 / 100$ person-years for the high category (Table 2). The mortality risk increased linearly according to $\mathrm{Ca}$ levels. There was no significant difference between the L-L and $\mathrm{M}-\mathrm{M}$ groups. On the other hand, the aIR in the $\mathrm{H}-\mathrm{H}$ group was significantly higher than that in the $M-M$ group (aIRR [95\% CI]: 1.51 [1.27-1.79]).

Among patients with $\mathrm{Ca}$ levels in the middle category at baseline, those who shifted to the high $(\mathrm{M}-\mathrm{H})$ category 3 months later were at a significantly higher risk compared with those who remained in the M-M group (Fig. 3b, middle). Among patients with Ca levels in the low category at baseline, those who shifted to the high

Table 2 alRs of mortality for patients whose parameters were maintained in the same category during the 3-month intervals

\begin{tabular}{llll}
\hline & \multicolumn{3}{l}{ Adjusted incidence rates $[\mathbf{9 5 \%} \mathbf{C l}], \mathbf{1 0 0}$ person-years } \\
\cline { 2 - 4 } & L-L group & M-M group & H-H group \\
\hline P & $7.4[5.4-9.4]$ & $4.9[4.4-5.3]$ & $11.1[6.4-15.7]$ \\
Ca & $3.7[1.5-5.8]$ & $4.5[3.9-5.2]$ & $6.8[6.1-7.5]$ \\
iPTH & $5.9[5.3-6.5]$ & $5.4[4.7-6.1]$ & $6.7[4.1-9.3]$ \\
\hline
\end{tabular}

Levels of each parameter were divided into three categories $(L, M$ and $H$ ); the middle category were defined as $4.0-7.0 \mathrm{mg} / \mathrm{dL}$ for $\mathrm{P}, 8.5-9.5 \mathrm{mg} / \mathrm{dL}$ for $\mathrm{Ca}$ and $200-500 \mathrm{pg} / \mathrm{mL}$ for $\mathrm{iPTH}$. For each 3-month interval ending at visit $t$, the changing patterns of MBD parameters during the previous 3-month interval from visit $t-2$ (baseline) to visit $t-1$ (3 months later) were evaluated. Incidence rates were adjusted for patients' characteristics (age, sex, primary kidney disease, diabetes, dialysis vintage, cardiovascular disease, lung disease, liver disease, malignancy and history of parathyroidectomy) and time-varying variables (VDRAs, phosphate binders, cinacalcet, albumin, hemoglobin, body mass index, $\mathrm{Kt} / \mathrm{V}$ and dialysate Ca concentration) alRs Adjusted incident rates, $\mathrm{Ca}$ Calcium, $H$ High, $i P T H$ Intact parathyroid hormone, $L$ low, $M$ Middle, MBD Mineral and bone disorder, $P$ Phosphorus, VDRA Vitamin $D$ receptor activator 
(a) Phosphorus

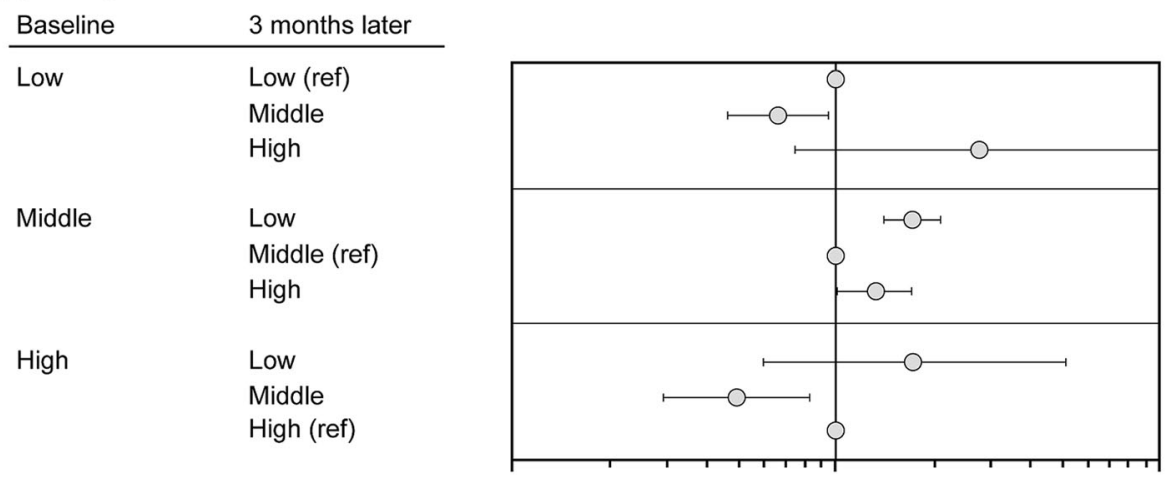

(b) Calcium

\begin{tabular}{ll} 
Baseline & 3 months later \\
\hline Low & $\begin{array}{l}\text { Low (ref) } \\
\text { Middle } \\
\text { High }\end{array}$ \\
Middle & $\begin{array}{l}\text { Low } \\
\text { Middle (ref) } \\
\text { High }\end{array}$ \\
High & Low \\
& $\begin{array}{l}\text { Middle } \\
\text { High (ref) }\end{array}$
\end{tabular}

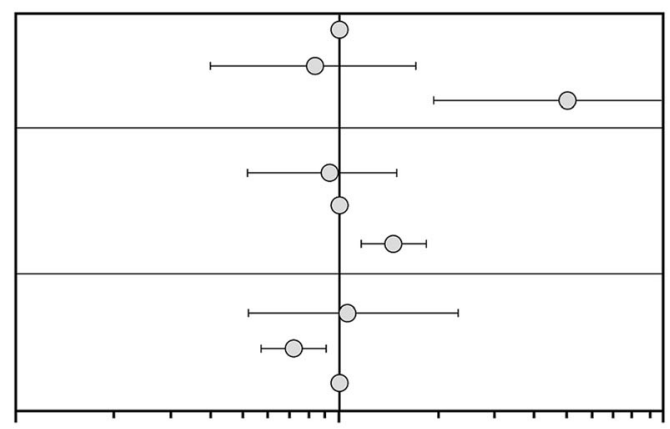

(c) Intact parathyroid hormone

\begin{tabular}{ll} 
Baseline & 3 months later \\
\hline Low & $\begin{array}{l}\text { Low (ref) } \\
\text { Middle } \\
\text { High }\end{array}$ \\
Middle & Low \\
& $\begin{array}{l}\text { Middle (ref) } \\
\text { High }\end{array}$ \\
High & Low \\
& Middle \\
& High (ref)
\end{tabular}

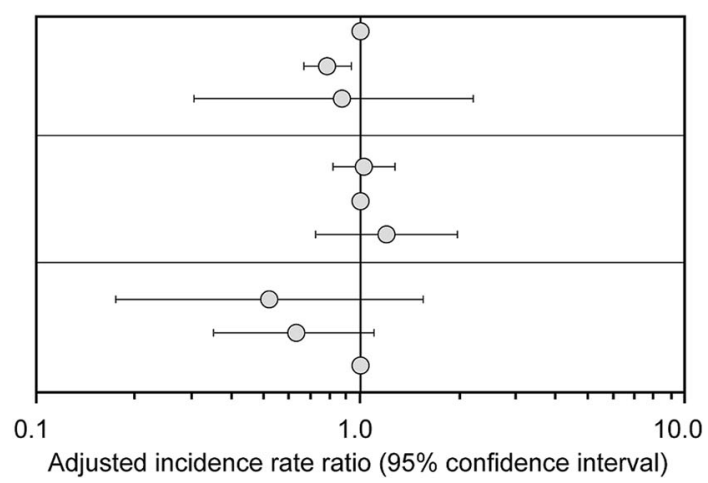

Fig. 3 alRRs for each combination of the values at baseline and 3 months later. Levels of each parameter were divided into three categories $(L, M$ and $\mathrm{H}$ ); the middle category were defined as $4.0-7.0 \mathrm{mg} / \mathrm{dL}$ for phosphorus, 8.5-9.5 mg/dL for calcium and 200-500 pg/mL for intact PTH. For each 3-month interval ending at visit $t$, the changing patterns of MBD parameters during the previous 3-month interval from visit $t-2$ (baseline) to visit $t-1$ (3 months later) were evaluated. Incidence rate ratios were adjusted for patients' characteristics (age, sex, primary kidney disease, diabetes, dialysis vintage, cardiovascular disease, lung disease, liver disease, malignancy and history of parathyroidectomy) and time-varying variables (VDRAs, phosphate binders, cinacalcet, albumin, hemoglobin, body mass index, Kt $N$ and dialysate $\mathrm{Ca}$ concentration). alRRs, adjusted incident rate ratios; $\mathrm{H}$, high; PTH, parathyroid hormone; L, low; M, middle; MBD, mineral and bone disorder; ref, reference; VDRA, vitamin D receptor activator

category had a higher risk of mortality compared with those who remained in the low (L-L) category; however, there was no significant difference between the L-L and L-M groups (Fig. 3b, top). Among patients with Ca levels in the high category at baseline, those who shifted to the middle (H-M) category had a lower risk of mortality compared with those who remained in the high $(\mathrm{H}-\mathrm{H})$ category (Fig. 3b, bottom).

Table 3 shows a comparison of the background characteristics of patients in the M-H group versus the M-L/ 
Table 3 Characteristics of patients shifted toward to high category in Ca level during the 3-month intervals

\begin{tabular}{|c|c|c|c|}
\hline & $M-L$ and $M-M$ groups & M-H group & SMD \\
\hline \multicolumn{4}{|l|}{ Demographics } \\
\hline Age, years & $62.0 \pm 20.2$ & $60.8 \pm 19.6$ & 0.06 \\
\hline Sex, female, \% & 36.5 & 40.4 & 0.15 \\
\hline Body mass index, $\mathrm{kg} / \mathrm{m}^{2}$ & $21.5 \pm 5.7$ & $21.4 \pm 5.6$ & 0.01 \\
\hline \multicolumn{4}{|c|}{ Cause of end-stage kidney disease, \% } \\
\hline Glomerulonephritis & 39.3 & 46.6 & \\
\hline Diabetic nephropathy & 29.4 & 22.6 & 0.17 \\
\hline Others & 31.4 & 30.8 & \\
\hline \multicolumn{4}{|l|}{ Comorbidities, \% } \\
\hline Diabetes mellitus & 36.9 & 28.5 & 0.18 \\
\hline Cardiovascular diseases & 58.6 & 57.8 & 0.02 \\
\hline Lung diseases & 7.2 & 7.0 & 0.01 \\
\hline Liver diseases & 12.8 & 13.8 & 0.03 \\
\hline Malignancies & 4.7 & 4.1 & 0.03 \\
\hline \multicolumn{4}{|l|}{ Dialysis } \\
\hline Log duration of dialysis, years & $0.7 \pm 0.7$ & $0.7 \pm 12.6$ & 0.14 \\
\hline $\mathrm{Kt} / \mathrm{V}$, single pool & $1.4 \pm 0.5$ & $1.5 \pm 0.5$ & 0.07 \\
\hline Dialysate calcium, mEq/L & $2.7 \pm 0.4$ & $2.8 \pm 0.4$ & 0.03 \\
\hline \multicolumn{4}{|l|}{ Laboratory data } \\
\hline Albumin, g/dL & $3.7 \pm 0.5$ & $3.7 \pm 0.5$ & 0.00 \\
\hline Hemoglobin, g/dL & $10.5 \pm 1.8$ & $10.6 \pm 1.8$ & 0.05 \\
\hline \multicolumn{4}{|l|}{ MBD-related characteristics } \\
\hline \multicolumn{4}{|l|}{ Serum parameters } \\
\hline $\mathrm{P}, \mathrm{mg} / \mathrm{dL}$ & $5.4 \pm 2.2$ & $5.6 \pm 2.2$ & 0.09 \\
\hline Log iPTH, pg/mL & $2.3 \pm 0.5$ & $2.3 \pm 0.5$ & 0.05 \\
\hline History of parathyroidectomy, $\%$ & 4.4 & 6.2 & 0.08 \\
\hline \multicolumn{4}{|c|}{ Prescription of MBD-related agents, \% } \\
\hline VDRAs & 79.8 & 86.4 & 0.22 \\
\hline Intravenous & 45.3 & 55.4 & \\
\hline Oral & 34.5 & 31.0 & \\
\hline Phosphate binders & 85.8 & 89.5 & 0.16 \\
\hline Both & 26.4 & 31.4 & \\
\hline Non-Ca-based & 15.0 & 17.3 & \\
\hline Ca-based & 44.4 & 40.7 & \\
\hline Cinacalcet & 19.3 & 28.2 & 0.21 \\
\hline
\end{tabular}

Values are presented as mean \pm standard deviation for continuous variables and proportions for categorical variables

Ca Calcium, $H$ High, iPTH Intact parathyroid hormone, $L$ Low, M Middle, MBD Mineral and bone disorder, $P$ Phosphorus, SMD Standard mean difference, VDRA

Vitamin D receptor activator

M-M groups. The former group was administered intravenous VDRA and cinacalcet more often than the latter groups (SMD: 0.22 and 0.21, respectively).

\section{Serum intact parathyroid hormone}

The aIRs for patients whose iPTH levels were maintained in the same category during the 3-month intervals were 5.9/100 person-years for the low category, 5.4/100 person-years for the middle category and 6.7/100 person-years for the high category (Table 2). Compared with patients whose iPTH levels were maintained in the middle (M-M) category, those whose iPTH levels were maintained in the low $(\mathrm{L}-\mathrm{L})$ and high $(\mathrm{H}-\mathrm{H})$ categories did not show any significant differences in mortality risk (aIRR [95\% CI]: 1.09 [0.93-1.27] and 1.24 [0.82-1.86], respectively). 
Among patients with iPTH levels in the middle category at baseline, those who shifted to the low (M-L) or high $(\mathrm{M}-\mathrm{H})$ category did not show any difference in the risk of mortality compared with the M-M group (Fig. 3c, middle). However, among patients with iPTH levels in the low category at baseline, those who shifted to the middle (L-M) category had a significantly lower risk of mortality compared with those who remained in the low (L-L) category (Fig. 3c, top). Among patients with iPTH levels in the high category at baseline, those who shifted to the middle $(\mathrm{H}-\mathrm{M})$ or low $(\mathrm{H}-\mathrm{L})$ category had a lower, albeit statistically insignificant, risk of mortality compared with those who remained in the high $(\mathrm{H}-\mathrm{H})$ category (Fig. 3c, bottom).

\section{Sensitivity analysis with 12-month intervals Serum phosphorus}

In the sensitivity analysis with 12-month intervals, the trend of aIRs among patients whose $\mathrm{P}$ levels were maintained in the same category was similar to that of the analysis with 3-month intervals (Table 4). However, the aIRR for the $\mathrm{H}-\mathrm{H}$ group was attenuated and was not significantly different (aIRR [95\% CI]: 1.81 [0.95-3.42]), and the significant differences observed between the L$\mathrm{M}$ and $\mathrm{L}-\mathrm{L} / \mathrm{H}-\mathrm{M}$ groups and between the $\mathrm{H}-\mathrm{M}$ and $\mathrm{H}-$ $\mathrm{H}$ groups in the analysis with 3-month intervals were not observed in the sensitivity analysis (Fig. 4a, top/ bottom).

\section{Serum Calcium}

In the sensitivity analysis with 12-month intervals, the $\mathrm{H}-\mathrm{H}$ group had a significantly higher risk of mortality compared with the M-M group (aIRR [95\% CI]: 1.25 [1.00-1.56] for the $\mathrm{H}-\mathrm{H}$ group); however, the magnitude of difference was smaller than in the analysis with 3month intervals (Table 4). There were no significant

Table 4 alRs of mortality for patients whose parameters were maintained in the same category during the 12-month intervals

\begin{tabular}{llll}
\hline & \multicolumn{3}{l}{ Adjusted incidence rates $[\mathbf{9 5 \%} \mathbf{C l}], \mathbf{~ 1 0 0 ~ p e r s o n - y e a r s ~}$} \\
\cline { 2 - 4 } & L-L group & M-M group & H-H group \\
\hline P & $8.7[4.7-12.7]$ & $5.6[5.1-6.1]$ & $10.1[3.7-16.5]$ \\
Ca & $7.6[3.1-12.2]$ & $5.3[4.4-6.3]$ & $6.7[5.9-7.5]$ \\
iPTH & $6.2[5.3-7.1]$ & $6.5[5.5-7.4]$ & $13.1[6.7-19.6]$ \\
\hline
\end{tabular}

Levels of each parameter were divided into three categories ( $L, M$ and $H$ ); the middle category were defined as $4.0-7.0 \mathrm{mg} / \mathrm{dL}$ for $\mathrm{P}, 8.5-9.5 \mathrm{mg} / \mathrm{dL}$ for $\mathrm{Ca}$ and $200-500 \mathrm{pg} / \mathrm{mL}$ for iPTH. For each 12-month interval ending at visit $t$, the changing patterns of MBD parameters during the previous 12-month interval from visit $t-2$ (baseline) to visit $t-1$ (12 months later) were evaluated. Incidence rates were adjusted for patients' characteristics (age, sex, primary kidney disease, diabetes, dialysis vintage, cardiovascular disease, lung disease, liver disease, malignancy and history of parathyroidectomy) and time-varying variables (VDRAs, phosphate binders, cinacalcet, albumin, hemoglobin, body mass index, $\mathrm{Kt} / \mathrm{V}$ and dialysate $\mathrm{Ca}$ concentration)

alRs Adjusted incident rates, $\mathrm{Ca}$ Calcium, $\mathrm{H}$ High, $i P T H$ Intact parathyroid hormone, $L$ Low, $M$ Middle, $M B D$ Mineral and bone disorder, $P$ Phosphorus; VDRA, vitamin $D$ receptor activator differences in mortality between the $\mathrm{L}-\mathrm{H}$ and $\mathrm{L}-\mathrm{L}$ groups and between the $\mathrm{H}-\mathrm{M}$ and $\mathrm{H}-\mathrm{H}$ groups in the sensitivity analysis (Fig. 4b, top/bottom).

\section{Serum intact parathyroid hormone}

In the sensitivity analysis with 12-month intervals, the $\mathrm{H}-\mathrm{H}$ group had a significantly higher risk of mortality compared with the M-M group (aIRR [95\% CI]: 2.03 [1.22-3.39]) (Table 4). There was no significant difference in mortality between the L-M and L-L groups in the sensitivity analysis (Fig. 4c, top).

\section{Discussion}

In the present study, we observed a significant association between all-cause mortality and changes in the 3month patterns of $\mathrm{P}$ and $\mathrm{Ca}$ in Japanese hemodialysis patients with SHPT. Our results show that evaluating the patterns of MBD-related parameters at shorter intervals can show significant association with mortality than at longer intervals, such as 6 or 12 months.

In the present study, we found consistent, bidirectional and significant associations between the changing patterns of serum $\mathrm{P}$ and all-cause mortality. Briefly, the patients who shifted from the middle category $(\mathrm{M}-\mathrm{H}$ and M-L groups) had a higher mortality than those who remained in the middle category ( $\mathrm{M}-\mathrm{M}$ group), and the patients who shifted to the middle category ( $\mathrm{H}-\mathrm{M}$ and L-M groups) had a lower mortality than those who persisted in the original category ( $\mathrm{H}-\mathrm{H}$ or $\mathrm{L}-\mathrm{L}$ group). Although these results clearly demonstrated the clinical relevance of maintaining P levels in the middle category, it is unclear whether the middle category $(4.0-7.0 \mathrm{mg} /$ $\mathrm{dL}$ ) used in the present study is optimal for other dialysis patients, as it is higher than the target ranges set in the JSDT $(3.5-6.0 \mathrm{mg} / \mathrm{dL})$ and Kidney Disease Outcomes Quality Initiative (KDOQI) $(3.55 .5 \mathrm{mg} / \mathrm{dL})$ guidelines and the safety zone in the COSMOS $(3.6-5.2 \mathrm{mg} /$ dL) study [7]. However, the optimal (middle) range in the present study was chosen according to the range of lower mortality risk in the previous study analyzed MBD-5D [6]. One of the reason of the difference of $P$ range between our study and clinical guidelines is that the study population of MBD-5D was limited to dialysis patients with SHPT who are at a higher risk of cardiovascular disease [16] and have the much severe condition of the serum $P$ value [6].

Higher serum $\mathrm{Ca}$ levels were consistently associated with higher all-cause mortality; the $\mathrm{L}-\mathrm{H}$ group had a higher risk than the L-L group, the $\mathrm{M}-\mathrm{H}$ group had a higher risk than the $\mathrm{M}-\mathrm{M}$ group and the $\mathrm{H}-\mathrm{M}$ group had a lower risk than the $\mathrm{H}-\mathrm{H}$ group. These results were in line with previous reports by JSDT, DOPPS and MBD-5D, suggesting that even in a short observation period of 3 months, high $\mathrm{Ca}$ levels are consistently 
(a) Phosphorus

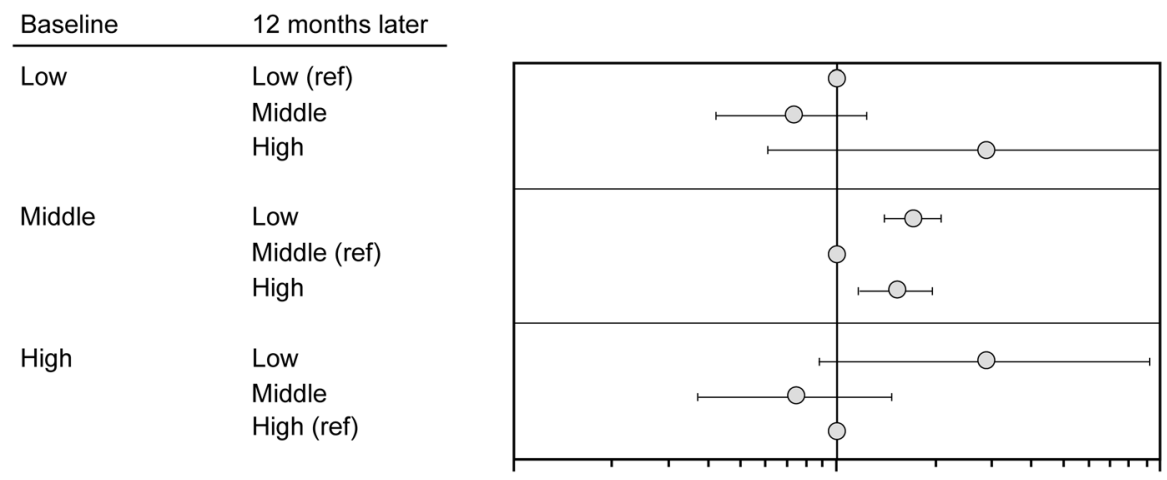

(b) Calcium

\begin{tabular}{ll} 
Baseline & 12 months later \\
\hline Low & $\begin{array}{l}\text { Low (ref) } \\
\text { Middle } \\
\text { High }\end{array}$ \\
Middle & $\begin{array}{l}\text { Low } \\
\text { Middle (ref) } \\
\text { High }\end{array}$ \\
High & Low \\
& $\begin{array}{l}\text { Middle } \\
\text { High (ref) }\end{array}$
\end{tabular}

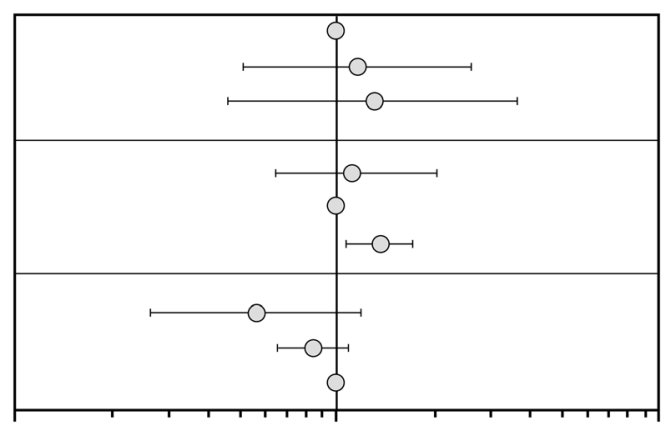

(c) Intact parathyroid hormone

\begin{tabular}{ll} 
Baseline & 12 months later \\
\hline Low & $\begin{array}{l}\text { Low (ref) } \\
\text { Middle } \\
\text { High }\end{array}$ \\
Middle & Low \\
& $\begin{array}{l}\text { Middle (ref) } \\
\text { High }\end{array}$ \\
High & Low \\
& Middle \\
& High (ref)
\end{tabular}

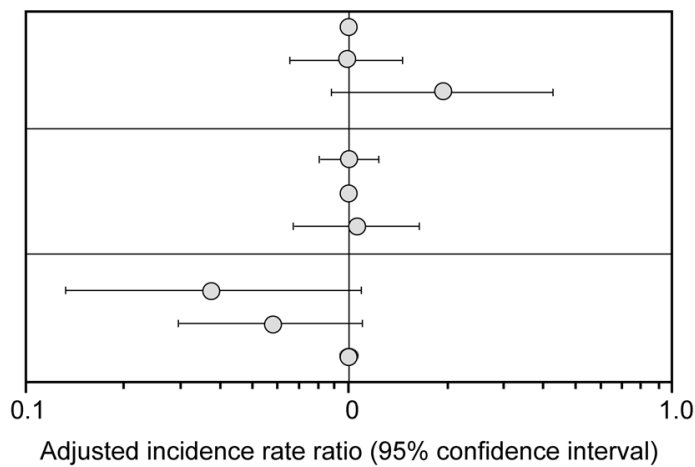

Fig. 4 alRRs for each combination of the values at baseline and 12 months later. Levels of each parameter were divided into three categories $(L$, $\mathrm{M}$ and $\mathrm{H}$ ); the middle category were defined as $4.0-7.0 \mathrm{mg} / \mathrm{dL}$ for phosphorus, 8.5-9.5 mg/dL for calcium and 200-500 pg/mL for intact PTH. For each 12-month interval ending at visit $t$, the changing patterns of MBD parameters during the previous 12-month interval from visit $t$-2 (baseline) to visit $t-1$ (12 months later) were evaluated. Incidence rate ratios were adjusted for patients' characteristics (age, sex, primary kidney disease, diabetes, dialysis vintage, cardiovascular disease, lung disease, liver disease, malignancy and history of parathyroidectomy) and timevarying variables (VDRAs, phosphate binders, cinacalcet, albumin, hemoglobin, body mass index, Kt $/ \mathrm{N}$ and dialysate Ca concentration). alRRs, adjusted incident rate ratios; $\mathrm{H}$, high; PTH, parathyroid hormone; L, low; M, middle; MBD, mineral and bone disorder; ref, reference; VDRA, vitamin D receptor activator

associated with higher mortality, and optimization of $\mathrm{Ca}$ levels is important for lower mortality. The middle category used for $\mathrm{Ca}$ in this study $(8.5-9.5 \mathrm{mg} / \mathrm{dL})$ was similar to the target range set in KDOQI $(8.4-9.5 \mathrm{mg} /$ $\mathrm{dL}$ ). The upper limit of the middle category for $\mathrm{Ca}$ in this study was lower than that of the target range set for $\mathrm{Ca}$ in the 2006 JSDT guidelines $(8.4-10.0 \mathrm{mg} / \mathrm{dL})$ [13]. However, the revised JSDT guidelines recommend that Ca levels in dialysis patients should be maintained at the lowest possible within the target range [17]. In this 
study, the mortality risk in the $\mathrm{H}-\mathrm{H}$ and $\mathrm{M}-\mathrm{H}$ group was significantly higher than that in the $\mathrm{M}-\mathrm{M}$ group. In Europe, the safety zone for $\mathrm{Ca}$ was indicated at 7.9 $9.5 \mathrm{mg} / \mathrm{dL}$ in maintenance dialysis patients [7]. In the USA, mortality risk in incident hemodialysis patients whose Ca levels were maintained at $9.5-10.2 \mathrm{mg} / \mathrm{dL}$ was significantly higher than that in patients whose Ca levels were maintained at $8.4-9.5 \mathrm{mg} / \mathrm{dL}$ [9]. Therefore, adequate caution should be exercised if $\mathrm{Ca}$ levels exceed $9.5 \mathrm{mg} / \mathrm{dL}$. We explored possible reasons for high $\mathrm{Ca}$ levels and found that patients in the $\mathrm{M}-\mathrm{H}$ group tended to use intravenous VDRA and cinacalcet more often (SMD > 0.2). These results supported the importance of avoiding hypercalcemia as recommended by the 2017 KDIGO guidelines [11].

For iPTH, no differences were observed in mortality risk between the $\mathrm{L}-\mathrm{L}, \mathrm{M}-\mathrm{M}$ and $\mathrm{H}-\mathrm{H}$ groups. These results are not consistent with reports from Europe and North America, where decreased iPTH levels correlated with higher cardiovascular risk and all-cause mortality $[8,10]$. One possible reason is that the target population in the MBD-5D study was limited to Japanese hemodialysis patients. In Japan, iPTH levels were maintained at a lower range compared with those in Western countries [18], and achievement of the iPTH target range led to low mortality [5]. Moreover, $42 \%$ of the patients had started cinacalcet during the study period [19]. In these patients, the MBD parameters, including PTH, Ca and P levels, reduced after cinacalcet administration [20]. Since the changing patterns of each MBD parameter were analyzed independently of other MBD parameters, the benefits of controlling PTH may have been underestimated.

Results of the sensitivity analysis with 12-month intervals were generally similar to those of the 3-month intervals. However, attenuation of aIRRs was observed in some groups, such as L-M and H-M for P levels and L$\mathrm{H}$ and $\mathrm{H}-\mathrm{M}$ for Ca levels. This could be due to possible misclassification of the MBD parameters during the observation period, as they can easily vary based on lifestyle, bone metabolism and medication.

The study has several strengths. First, MBD-5D was performed as a prospective case cohort study, which enabled both elaborate and repeated data collection with few missing data and powerful outcome measurements with less systematic biases at the same time. Second, participants of this study were restricted to hemodialysis patients with SHPT who were generally at risk of abnormal MBD parameters. Therefore, the results of this study can be applied to patients requiring treatment for CKD-MBD. Third, MBD-5D prospectively collected MBD parameters at 3-month intervals, which enhanced the probability of observing significant variations in MBD parameters associated with mortality that might have been overlooked in previous studies evaluating exposures and outcomes at 6- or 12-month intervals.

The study has several limitations. First, it is not possible to measure unknown confounding factors. Second, there is still a possibility of misclassification of MBD parameters, as they were collected every 3 months only and changes in MBD parameters during each 3-month interval could not be detected. The 2017 KDIGO guidelines recommend that treatment for MBD should be considered based on serial assessment of MBD parameters [11]. On the other hand, evaluating variations at intervals shorter than 3 months might result in increased contamination because bone turnover generally takes place in a 3-month cycle. Third, we analyzed the changes in each MBD parameter independently to simplify the analysis model. On the other hand, the 2017 KDIGO guidelines recommend that MBD parameters should be interpreted together. In clinical practice, it is almost impossible to modify only one of the MBD parameters; therefore, caution is warranted while applying the results of this study to clinical practice. Fourth, iPTH levels in Japanese hemodialysis patients were at a lower range compared with patients in Western countries. Hence, the association between changes in iPTH levels and mortality might not be detectable in a Japanese population. Fifth, pathophysiologically, the short-term changes in MBD parameters might reflect clinical practices in MBD treatment, such as therapeutic inertia in refractory patients, and thus overestimate the difference in mortality. To verify the results of this study, a new clinical study should be conducted excluding such patients. Sixth, we collected data on MBD parameters every 3 months, so these may fluctuated in the period, although we evaluated in ther shortest interval cmparing with the existing suduie [7, $8,10]$. Also, the backgrond causing the observed shifts (e.g., therapy driven, disease progression) are unknown.Finally, it is unknown whether the changes in MBD parameters are due to natural course, medication or other reasons; therefore, it is not well established whether phosphate-lowering therapy has the same effect on mortality as observed in patients with spontaneous decrease in serum $P$.

\section{Conclusions}

Our study emphasizes the importance of the management of MBD parameters again, especially for serum $\mathrm{P}$ which may affect the patients prognosis only with the short term deviation, should be managed in the appropriate range avoiding the risk of hypercalcemia for better prognosis in dialysis patients with SHPT. 


\section{Abbreviations}

alRRs: Adjusted Incidence Rate Ratios; alRs: Adjusted Incidence Rates; Ca: Calcium; Cls: Confidence Intervals; CKD-MBD: Chronic Kidney DiseaseMineral and Bone Disorder; H: High; iPTH: Intact Parathyroid Hormone; JSDT: Japanese Society for Dialysis Therapy; KDIGO: Kidney Disease Improving Global Outcomes; KDOQI: Kidney Disease Outcomes Quality Initiative; L: Low; M: Middle; MBD: Mineral and Bone Disorder; MBD5D: Mineral and Bone Disorder Outcomes Study for Japanese CKD Stage 5D Patients; P: Phosphorus; ref: Reference; SHPT: Secondary Hyperparathyroidism; SMD: Standard Mean Difference; VDRA: Vitamin D Receptor Activator

\section{Acknowledgements}

We would like to thank the MBD-5D study advisory investigators, Masashi Suzuki (Shinrakuen Hospital), Yoshindo Kawaguchi (Shiomidai Hospital), Akira Saito (Shonan Tobu Sougo Hospital), Yoshiki Nishizawa (Osaka City University Graduate School of Medicine), Yusuke Tsukamoto (Itabashi Chuo Medical Center), Satoshi Kurihara (Tsukinomori Clinic), Takashi Akiba (Tokyo Women's Medical University), Eriko Kinugasa (Showa University Northern Yokohama Hospital), Yuzo Watanabe (Kasugai Municipal Hospital), Yoshihiro Tominaga (Nagoya Daini Red Cross Hospital), Takashi Shigematsu (Wakayama Medical University), Masaaki Inaba (Osaka City University Graduate School of Medicine), Jun Minakuchi (Kawashima Hospital), Hideki Hirakata (Fukuoka Red Cross Hospital), Keitaro Yokoyama (Jikei University School of Medicine), Naoki Kimata (Tokyo Women's Medical University), Fumihiko Koiwa (Showa University Fujigaoka Hospital), Ryoichi Ando (Musashino Red Cross Hospital), Junichiro J. Kazama (Niigata University), Takatoshi Kakuta (Tokai University School of Medicine), Hirotaka Komaba (Tokai University School of Medicine), Daijo Inaguma (Nagoya Daini Red Cross Hospital), Eiji Ishimura (Osaka City University Graduate School of Medicine), Hideki Tahara(Osaka City University Graduate School of Medicine), Kazuhiko Tsuruya (Kyushu University), Akira Fujimori (Konan Hospital) and Ryo Kido (Inagi Municipal Hospital).

The following investigators also participated in this study: Nobuo Hashimoto $(H \cdot N \cdot M E D I C)$, Mari Ishida (Kitasaito Hospital), Toshiyuki Date (Date Clinic), Kiyotaka Yabuki (Yabuki Hospital), Hideki Tanida (Tendo Onsen Yabuki Clinic), Fumitoshi Yamauchi (San-ai Hospital), Mikihiko Fujishima (Yahaba Clinic), Tomohito Matsunaga (Eijinkai Hospital), Jun Urae (Ishinomaki Clinic), Hiroshi Kawaguchi (Iwaki Urological Hospital), Ikuo Takahashi (Kisen Hospital), Yoshiko Tanaka (Shinjuku Ishikawa Clinic), Hideo Kobayashi (Suda Clinic), Maki Takahashi (Suda Naika Clinic), Tatsuya Nonaka (Seishokai Memorial Hospital), Hideto Emoto (Tokai Hospital), Kyosuke Nishio (Shinkoiwa Clinic), Atsushi Hayama (Moriyama Rehabilitation Hospital), Toshio Shinoda (Kawakita General Hospital Dialysis Center), Takashi Kono (Mihama Narita Clinic), Takahiro Mochizuki (Kameda Medical Center), Yasuo Kimura (Shin-kashiwa Clinic), Noriyoshi Murotani (Chiba Social Insurance Hospital), Satoshi Yamaguchi (Asahi Hospital), Taichi Nakanishi (Kurihama Clinic), Kiyoshi Ozawa (Yokosuka Clinic), Takashi Nagaoka (Sagamihara Clinic), Takao Suga (Bousei Hiratsuka Clinic), Masakazu Suda (Suda Medical Clinic), Yoshikazu Goto (Saiyu Soka Hospital), Michio Kuwahara (Shuwa General Hospital Hemodialysis Clinic), Hiromi Shimoyama (Yuai Clinic), Kimihiko Matsuyama (Misato Kenwa Clinic), Kazue Ueki (Toho Hospital), Kyoko Ito (Heisei Hidaka Clinic), Katsuhiko Miyamoto (Seseragi Hospital), Takashi Ishizu (Tukuba Central Hospital), Shuichi Kikuchi (Ohba Renal Clinic), Masaki Kobayashi (Tokyo Medical University Ibaraki Medical Center), Mitsuyoshi Furuhashi (Maruyama Hospital), Masanori Wakabayashi (Bousei Dai-ichi Clinic), Kazuyoshi Nakamura (Fujidaiichi Clinic), Hirotake Kasuga (Kaikoukai Central Clinic), Itsuo Yokoyama (Nagoya Memorial Foundation Narumi Clinic), Chikao Yamazaki (Masuko Clinic SUBARU), Kijun Nagata (Sawada Hospital), Yasumasa Kawade (Suzuka Kidney Clinic), Toshiaki Kawanaka (Ishikiriseiki Hospital), Yoshihiro Tsujimoto (Inoue Hospital), Mikio Okamura (Ohno Memorial Hospital), Shigeki Okada (Okada Clinic), Senji Okuno (Kidney Center Shirasagi Clinic), Harumi Nagayama (Nagayama Hemodialysis Clinic), Shuji Okazaki (Nagayama Hospital), Yoshinori Tone (Fujii Clinic), Ibuki Yajima (Ibuki Clinic), Kouji Shibuya (Sumiyoshigawa Hospital), Kunihiko Yoshiya (Hara Genitourinary Hospital), Morihiro Kondou (Otowa Kinen Hospital), Satoru Yamazaki (Tojinkai Hospital), Ryoichi Miyazaki (Fujita Memorial Hospital), Katsuhiko Arimoto (Shigei Medical Research Hospital), Misaki Moriishi (Nakajima Tsuchiya Clinic), Takahito Nasu (Tokuyama Central Hospital), Seiichi Obayashi (Kinashi Obayashi Hospital), Yuzuru Sato (Sato Junkankika Naika), Takao Tanaka (Ohji Hospital), Hidetoshi Nakamura (Kokura Daiichi Hospital), Nobuhiko Koga (Shin-Koga Clinic), Harumichi Higashi (St. Mary's Hospital), Kougi Yuu (Takahashi Naika Clinic), Asako Kitamura (Chikuho Social Insurance Hospital), Tomoji Matsumae (Murakami Memorial
Hospital), Katsushige Abe (Jinikai Hospital), Masahiro Kawatomi (Kawatomi Internal Medicine Clinic), Chisa Nogami (Kumamoto Urological Hospital), Etsuo Yoshidome (Ikeda Hospital), Shinyu Miyagi (Okinawa Daiichi Hospital), Satoshi Nakazato (Chibana Clinic), Yoshiki Shiohira (Tomishiro Central Hospital) and Kiyoyuki Tokuyama (Tokuyama Clinic).

\section{Authors' contributions}

CK, NF, YO, SF1, SA, TN and MW conceived and designed the study. CM planned and performed statistical analyses. CK, NF and CM drafted the manuscript. YO, SF1, SA, TN and MW revised the manuscript. NF, YO, SF1 and TN provided administrative, technical or material support. MF, SF2 and TA supervised the preparation of the manuscript. All authors read and approved the final manuscript.

\section{Funding}

The MBD-5D study was funded by KKC.

\section{Availability of data and materials}

The datasets used and/or analyzed during the current study are available from the corresponding author on reasonable request.

\section{Ethics approval and consent for participate}

The study protocol was approved by the central ethics committee at Kobe University's School of Medicine. Informed consent was not mandatory according to the ethical guidelines for epidemiological research in Japan. Anonymized data was collected and analyzed. The study is registered at ClinicalTrials.gov (NCT00995163).

\section{Consent for publication}

Not applicable.

\section{Competing interests}

CK, SA, TN and MW are employees of Kyowa Kirin Co. Itd., (KKC). NF received grants from KKC. CM and YO do not have any conflicts of interest to declare. SF1 has acted as a scientific advisor for KKC. SF2 has acted as a scientific advisor for and has received grants from KKC. MF has received consulting fees from KKC and Ono Pharmaceutical; lecture fees from KKC, Bayer, Torii Pharmaceutical and Ono Pharmaceutical; and grants from KKC, Bayer and Ono Pharmaceutical. TA has received personal fees from KKC, Astellas Pharma, Bayer, Fuso Pharmaceutical, Japan Tobacco, Ono Pharmaceutical, NIPRO, Chugai Pharmaceutical, Kissei Pharmaceutical, Torii Pharmaceutical and Otsuka Pharmaceutical.

\section{Author details}

${ }^{1}$ Medical Affairs Department, Kyowa Kirin Co., Ltd, Otemachi Financial City Grand Cube, 1-9-2 Otemachi, Chiyoda-ku, Tokyo 100-0004, Japan. ${ }^{2}$ Department of Internal Medicine (Nephrology Unit), Hyogo Prefectural Nishinomiya Hospital, Nishinomiya, Japan. ${ }^{3}$ Department of Healthcare Epidemiology, School of Public Health, Faculty of Medicine, Kyoto University, Kyoto, Japan. ${ }^{4}$ Department of Pediatrics, Kobe City Medical Center General Hospital, Kobe, Japan. Institute for Health Outcomes and Process Evaluation Research (iHope International), Kyoto, Japan. ${ }^{6}$ Human Health Sciences, Kyoto University Graduate School of Medicine, Kyoto, Japan. ${ }^{7}$ The Keihanshin Consortium for Fostering the Next Generation of Global Leaders in Research (K-CONNEX), Kyoto, Japan. ${ }^{8}$ Division of Nephrology, Endocrinology and Metabolism, Tokai University School of Medicine, Isehara, Japan. ${ }^{9}$ Division of Nephrology, Department of Medicine, Showa University School of Medicine, Tokyo, Japan.

\section{Received: 25 February 2020 Accepted: 2 October 2020}

Published online: 12 October 2020

\section{References}

1. Young EW, Akiba T, Albert JM, McCarthy JT, Kerr PG, Mendelssohn DC, et al. Magnitude and impact of abnormal mineral metabolism in hemodialysis patients in the Dialysis Outcomes and Practice Patterns Study (DOPPS). Am J Kidney Dis. 2004;44:34-8.

2. Block GA, Klassen PS, Lazarus JM, Ofsthun N, Lowrie EG, Chertow GM. Mineral metabolism, mortality, and morbidity in maintenance hemodialysis. J Am SocNephrol. 2004;15:2208-18. 
3. Kalantar-Zadeh K, Kuwae N, Regidor DL, Kovesdy CP, Kilpatrick RD, Shinaberger CS, et al. Survival predictability of time-varying indicators of bone disease in maintenance hemodialysis patients. Kidney Int. 2006;70: 771-80.

4. Tentori F, Blayney MJ, Albert JM, Gillespie BW, Kerr PG, Bommer J, et al. Mortality risk for dialysis patients with different levels of serum calcium, phosphorus, and PTH: the Dialysis Outcomes and Practice Patterns Study (DOPPS). Am J Kidney Dis. 2008:52:519-30.

5. Taniguchi M, Fukagawa M, Fujii N, Hamano T, Shoji T, Yokoyama K, et al. Serum phosphate and calcium should be primarily and consistently controlled in prevalent hemodialysis patients. TherApher Dial. 2013;17:221-8.

6. Fukagawa M, Kido R, Komaba H, Ohnishi Y, Yamaguchi T, Hasegawa T, et al. Abnormal mineral metabolism and mortality in hemodialysis patients with secondary hyperparathyroidism: evidence from marginal structural models used to adjust for time-dependent confounding. Am J Kidney Dis. 2014;63:979-87.

7. Fernández-Martín JL, Martínez-Camblor P, Dionisi MP, Floege J, Ketteler M, London $\mathrm{G}$, et al. Improvement of mineral and bone metabolism markers is associated with better survival in haemodialysis patients: the COSMOS study. Nephrol Dial Transplant. 2015;30:1542-51.

8. Merle E, Roth H, London GM, Jean G, Hannedouche T, Bouchet JL, et al. Low parathyroid hormone status induced by high dialysate calcium is an independent risk factor for cardiovascular death in hemodialysis patients. Kidney Int. 2016;89:666-74.

9. Soohoo M, Feng M, Obi Y, Streja E, Rhee CM, Lau WL, et al. Changes in markers of mineral and bone disorders and mortality in incident hemodialysis patients. Am J Nephrol. 2016;43:85-96.

10. Villa-Bellosta R, Rodriguez-Osorio L, Mas S, Abadi Y, Rubert M, de la Piedra C, et al. A decrease in intact parathyroid hormone (iPTH) levels is associated with higher mortality in prevalent hemodialysis patients. PLoS One. 2017;12:e0173831.

11. Kidney Disease: Improving Global Outcomes (KDIGO) CKD-MBD Update Working Group. KDIGO. Clinical Practice Guideline Update for the Diagnosis, Evaluation, Prevention, and Treatment of Chronic Kidney Disease-Mineral and Bone Disorder (CKD-MBD). Kidney IntSuppl. 2017;2017(7):1-59.

12. Fukuhara S, Akizawa T, Fukagawa M, Onishi Y, Yamaguchi T, Hasegawa T, et al. Mineral and bone disorders outcomes study for Japanese chronic kidney disease stage 5D Patients: rationale and study design. TherApher Dial. 2011;15:169-75.

13. Guideline Working Group, Japanese Society for Dialysis Therapy. Clinical practice guideline for the management of secondary hyperparathyroidism in chronic dialysis patients. TherApher Dial. 2008;12:514-25.

14. Payne RB, Little AJ, Williams RB, Milner JR. Interpretation of serum calcium in patients with abnormal serum proteins. Br Med J. 1973;4:643-6.

15. Cohen J. Statistical power analysis for the behavioral sciences. 2nd ed. Hillsdale: Lawrence Erlbaum Associates Publishers; 1988.

16. Fujii H. Association between Parathyroid Hormone and Cardiovascular Disease. TherApher Dial. 2018;22:236-41.

17. Fukagawa M, Yokoyama K, Koiwa F, Taniguchi M, Shoji T, Kazama JJ, et al. Clinical practice guideline for the management of chronic kidney diseasemineral and bone disorder. TherApher Dial. 2013;17:247-88.

18. Tentori F, Wang M, Bieber BA, Karaboyas A, Li Y, Jacobson SH, et al. Recent changes in therapeutic approaches and association with outcomes among patients with secondary hyperparathyroidism on chronic hemodialysis: the DOPPS study. Clin J Am SocNephrol. 2015;10:98-109.

19. Akizawa T, Kurita N, Mizobuchi M, Fukagawa M, Onishi Y, Yamaguchi T, et al. PTH-dependence of the effectiveness of cinacalcet in hemodialysis patients with secondary hyperparathyroidism. Sci Rep. 2016;6:19612.

20. Akizawa T, Kido R, Fukagawa M, Onishi Y, Yamaguchi T, Hasegawa T, et al. Decreases in PTH in Japanese hemodialysis patients with secondary hyperparathyroidism: associations with changing practice patterns. Clin J Am SocNephrol. 2011;6:2280-8.

\section{Publisher's Note}

Springer Nature remains neutral with regard to jurisdictional claims in published maps and institutional affiliatio

\section{Ready to submit your research? Choose BMC and benefit from}

- fast, convenient online submission

- thorough peer review by experienced researchers in your field

- rapid publication on acceptance

- support for research data, including large and complex data types

- gold Open Access which fosters wider collaboration and increased citations

- maximum visibility for your research: over $100 \mathrm{M}$ website views per year

At BMC, research is always in progress.

Learn more biomedcentral.com/submissions 